\title{
Design for an on-line computerized system for MMPI interpretation
}

\author{
DALE A. MILLER, JAMES H. JOHNSON, DANIEL E. KLINGLER, \\ THOMAS A. WILLIAMS, and RONALD A. GIANNETTI \\ Veterans Administration Hospital, Salt Lake City, Utah 84148 and \\ University of Utah College of Medicine, Salt Lake City, Utah 84148
}

\begin{abstract}
The development of an on-line MMPI interpretative program is outlined. Profiles interpreted by this program are first examined to determine whether a standard or locally known profile type fits. If so, an appropriate narrative report is printed. If there is no match with a known profile type, statements from several scale-by-scale interpretative sources are organized into a logical report. Methods have been developed to eliminate duplication and contradiction from different sources of information. Examples of output from this program are presented and advantages of the program are discussed.
\end{abstract}

In the past decade, the use of automated systems for MMPI scoring and interpretation has increased greatly. Lachar (1974a) listed six MMPI interpretation programs developed to make automated clinical interpretations: Dunlop (1966), Finney (1966), Fowler (1967), Gilberstadt (1970), Pearson and Swenson (1967), and Caldwell (Note 1). More recently, MMPI interpretation systems have been reported by Gehring and Blaser (1972) and Lachar (1974b). Automated MMPI interpretation is growing in popularity because: (1) interpretation is done according to consistent rules applied to all profiles, (2) interpretation is based on a wider variety of sources than the clinician is able to integrate simultaneously, and (3) automated interpretation often results in substantial savings of clinical staff time.

Johnson, Giannetti, and Williams (1976) noted that most of the current MMPI interpretative programs are not applicable for implementation with an on-line computer system. However, an automated on-line MMPI administration and scoring system has been reported by Lushene, O'Neil, and Dunn (1974), who found that computerized administration with an on-line system produces data that are as valid as those obtained from conventional administration of the test. They conclude that the full benefits of ease of administration and immediate scoring and interpretation of the MMPI are obtained only through the use of an on-line computer system.

Eichman (1972) noted that it has been difficult to conduct validity research on MMPI interpretative programs because computer program listings for three of the four most widely used systems have not been published. Recently, there has been an increase in the publication of validity studies on MMPI interpretative systems. Grayson and Backer (1972) compared the accuracy of MMPI scale scores reported from four com-

Request for reprints should be addressed to James $H$. Johnson, Systems and Evaluation Unit, VA Hospital, Salt Lake City, Utah 84148. mercial MMPI scoring and interpretation services and found the agencies to be relatively accurate in scoring. Studies conducted at several of the commercial MMPI interpretation services suggest that narratives produced from these systems are generally perceived by clinicians as accurate $70 \%$ to $90 \%$ of the time (Lachar, 1974a; Webb, 1970; Webb, Miller, \& Fowler, 1969, 1970; Lushene \& Gilberstadt, Note 2). Bringmann, Balance, and Geisbrecht (1972) found that computerized interpretations of elevated MMPI profiles were rated as more accurate than interpretations made by psychological technicians; however, computerized interpretations were rated as equal in accuracy to the technicians' interpretations for normal profiles. Lachar, Klinge, and Grisell (1976) found that their interpretation system could be improved for patients aged 12 to 17 years by using adolescent scoring norms.

However, Goldstein and Reznikoff (1972) report that computerized interpretations of ten misclassified chronically ill patients as hypochondriacal. In addition, Hedlund, Morgan, and Master (1972) found that descriptive statements printed by a slightly modified version of the Mayo Clinic automated MMPI program did not correlate significantly with independent clinical reports. Most reports are favorable, but two types of studies have been reported rarely: (1) evaluations of MMPI interpretation systems by independent researchers and (2) comparisons of several automated MMPI interpretation systems by independent researchers. Thus, there appears to be a need for published automated MMPI interpretative programs that can be subjected to independent validity examination and comparison.

This paper describes an on-line MMPI interpretation program developed at the Salt Lake City Veterans Administration Hospital and the University of Utah College of Medicine. This program directly gathers responses to the MMPI items from patients using interactive cathode ray tube terminals. The MMPI report is printed out by issuing brief commands from the terminal. 


\section{METHOD}

In developing this program it was assumed that not all MMPI profiles may be best interpreted using the same technique. We thought it profitable to have several sources of interpretative material available, so that the best method could be applied to each patient. Sources of interpretative information included: (1) Stelmacher's (Note 3) standard profile descriptions, (2) interpretative rules for classifying profiles (Gilberstadt \& Duker, 1965; Marks \& Seeman, 1963), (3) Carson's (1969) interpretation manual, (4) Swenson's (1963) scale-by-scale analysis, (5) Dahlstrom and Welsh's (1972) A and R scales, (6) Wiggins' (1971) content scales, (7) Block's (1965) ego control and ego resiliency scales, and (8) profile types that are commonly encountered at the Salt Lake City Veterans Administration Hospital.

A second basic assumption was that alternative methods of MMPI interpretation (e.g., nationally known profile types, locally known types, scale-by-scale analysis, linear combinations) could be placed in a preference hierarchy. The preferred methods would be used when applicable, and the less favored methods would be used in remaining cases. Goldberg (1965) and Nichols (1974) found linear combinations effective in separating psychotic patients from neurotics. However, in our research such combinations have not been found effective in making specific predictions required for the generation of psychological reports. Therefore, linear combinations were excluded as a method of analysis. Profile analysis was chosen as the most widely accepted method for making specific predictions from MMPI results. If the MMPI could not be interpreted

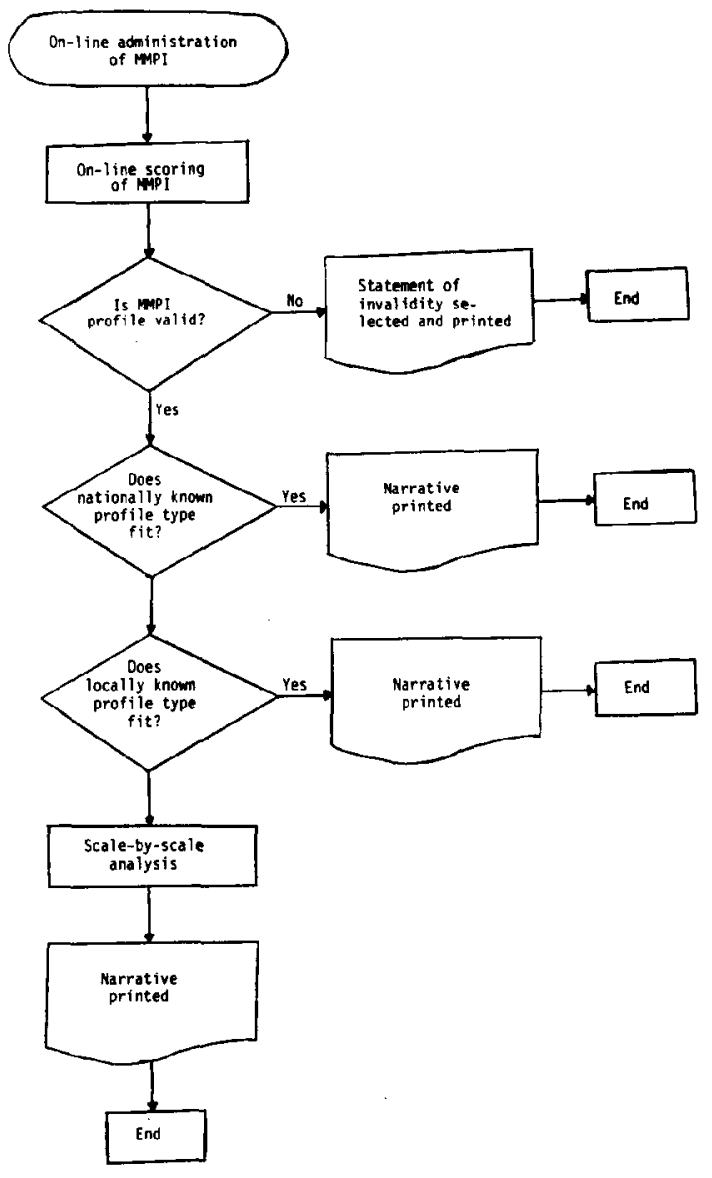

Figure 1. Flow of MMPI interpretative program. with eight nationally or locally known profile types, then a scale-by-scale interpretation was used.

\section{FLOW OF THE COMPUTER PROGRAM}

The overall flow of this MMPI interpretation program is shown in Figure 1. After the MMPI is administered and scored, the profile is examined for validity, using the three standard scales $(\mathrm{L}, \mathrm{F}$, and $\mathrm{K})$ and the Gough (1950) $F-K$ dissimulation index. If the profile is clearly invalid, a statement to that effect is printed, and no further interpretation is done. Otherwise, a statement regarding the subject's general approach to the test-taking situation is printed, and interpretation continues.

The MMPI program was designed to examine the results of each MMPI protocol submitted to determine whether the rules for any standard profile type (Gilberstadt \& Duker, 1965; Marks \& Seeman, 1963) are met. If so, the appropriate narrative is printed without further interpretation. If such rules are not met, the MMPI is then examined to see whether any locally known profile applies. If so, the appropriate narrative is also printed without further interpretation.

However, studies have shown that profile interpretations can be made for not more than $70 \%$ of the patient population (Gilberstadt, 1969; Gynther, Altman, \& Sletten, 1973). For the remaining patients, scale-by-scale analysis is used as the best available method of interpretation. Because of the diverse interpretative sources used for the scale-by-scale analysis, rules have been developed to prevent contradictions, and potentially conflicting descriptors are placed in mutually exclusive classes. Whenever descriptors from mutually exclusive classes are called up together, neither descriptor is printed. For example, the word "outgoing" never appears in the same report with the word "withdrawn." (See Figure 2.) To prevent repetition, each descriptor is tagged by the program to insure that it does not appear twice in a report. Also, single words or phrases have been chosen to represent sets of synonymous descriptors. As a result, most duplication is eliminated.

In examining the interpretative material from scaleby-scale sources, one finds single words, phrases, or sentences relating to many different areas of patient functioning. In order to promote readability of the report, it was decided to integrate material from diverse sources according to topic areas. These topics were then arranged in the order generally found in psychological reports as follows: current distress, symptoms, feelings, attitudes and character, defenses, interpersonal relations, behavior, vocational and marital adjustment, and prognosis. Within each topic, a series of sentence frameworks has been developed through which interpretative material may be presented. For example, one framework reads, "The MMPI profile suggests__ distress ( filled with a word indicating level of severity, while the 


\begin{tabular}{|c|c|c|c|c|c|}
\hline Category/Elevation & Current Distress & & Symptoms & Feelings & Attitudes and Thoughts \\
\hline PT under 45T & Lack of worries ${ }^{1}$ & & & & $\begin{array}{l}\text { Self-confident relaxed } \\
\text { attitude toward responsi- } \\
\text { bilities }^{21}\end{array}$ \\
\hline \multicolumn{6}{|l|}{ PT 45-60T } \\
\hline PT $61-65 T$ & $\begin{array}{l}\text { Tends to worry over } \\
\text { minor problems }\end{array}$ & & & & Self-critical ${ }^{2}$ \\
\hline PT 66-75T & Worry anxiety ${ }^{2}$ & & Obsessional & & $\begin{array}{l}\text { Indecisive }^{12} \\
\text { Self-critical }^{22}\end{array}$ \\
\hline PT 76-85T & $\begin{array}{l}\text { Worrisome, appre- } \\
\text { hensive, moderate } \\
\text { to severe levels of } \\
\text { anxiety and tension } \\
\text { make simple routine } \\
\text { tasks difficult }{ }^{2}\end{array}$ & & Obsessional & & $\begin{array}{l}\text { Indecisive, often religious } \\
\text { and moralistic }{ }^{12} \\
\text { Self-critical }^{22}\end{array}$ \\
\hline \multirow[t]{3}{*}{ PT over $85 \mathrm{~T}$} & $\begin{array}{l}\text { Severe anxiety \& } \\
\text { tension may make } \\
\text { routine tasks im- } \\
\text { possible; agitated, } \\
\text { ruminative, nervous }{ }^{2}\end{array}$ & & $\begin{array}{l}\text { Chronic obsessions } \\
\text { and/or compulsions } \\
\text { and/or phobias may } \\
\text { be present. }\end{array}$ & $\begin{array}{l}\text { Disabling guilt } \\
\text { feelings may be } \\
\text { present }^{22}\end{array}$ & $\begin{array}{l}\text { Constant rehashing of } \\
\text { problems and possible } \\
\text { solutions } \\
\text { Meticulous, moralistic }{ }^{12} \\
\text { Very self-critical }^{2}\end{array}$ \\
\hline & \multicolumn{4}{|c|}{ Sample Content Classes } & \\
\hline & & $\begin{array}{r}1 \\
2 \\
11 \\
12 \\
21 \\
22\end{array}$ & $\begin{array}{l}\text { Lack of worries } \\
\text { Worry } \\
\text { Daring, impulsive, dec } \\
\text { Cautious, convention } \\
\text { Self-satisfaction } \\
\text { Feels inadequate }\end{array}$ & $\begin{array}{l}\text { ne } \\
\text { ndecisive }\end{array}$ & \\
\hline
\end{tabular}

Figure 2. Samples of organized interpretative statements for scale-by-scale analysis.

remaining blanks are filled with descriptors of the kinds of distress (depression, anxiety, insomnia, etc.) that apply. These sentence frameworks are constructed so that all possible combinations of descriptors can logically fit. A potential problem with this approach is that information may not be available to fill all the frameworks. Therefore, the sentences are constructed so that the report will flow smoothly even with omissions. In some cases, different sentence frameworks can sound very similar if filled in certain ways. Therefore, special rules have been written so that only one such sentence is printed in such cases. Finally, the sequence of sentence frameworks is divided into appropriate paragraphs. Thus, there is a basic group of sentence frameworks designed to appear in the same order in every scale-byscale report; however, these sentences are filled with many different descriptors. In some cases, MMPI scale scores dictate the insertion of additional, complete sentences at appropriate locations in the report. As a result, each MMPI narrative printed is unique to the individual patient. Through this program, concise, internally consistent psychological reports are generated, regardless of whether profile or scale-by-scale analysis is used.

\section{EXAMPLES}

Two samples of the output from this MMPI interpretation program are shown in Figures 3,4,5, and 6. The first example represents a standard MMPI profile interpretation; the second is based on an integration of scale-by-scale sources. Both methods yield readable, organized, and accurate reports. However, the report

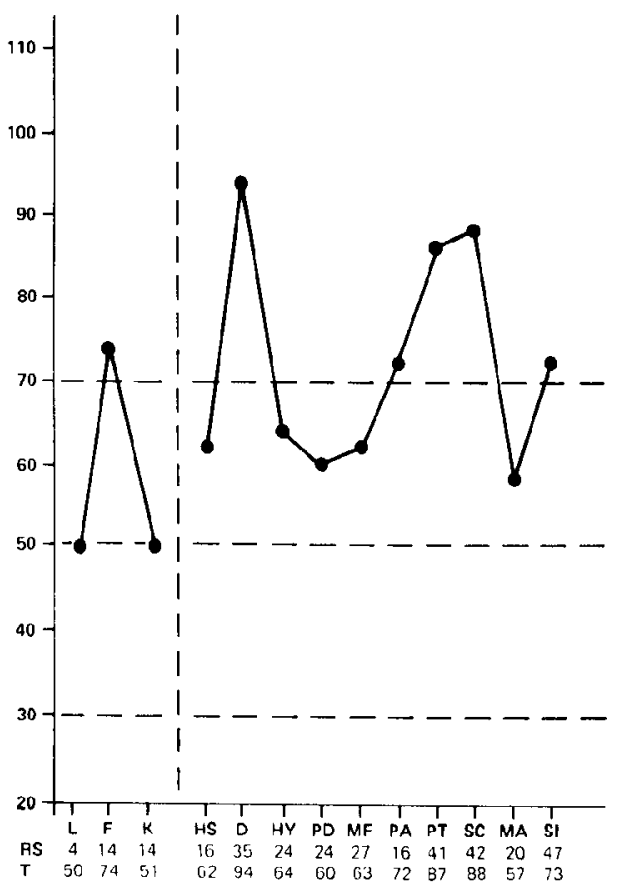

Figure 3. MMPI scores resulting in standard profile interpretation. 


\section{PATIENT NAME}

M M P I INTERPRETATION

THE PATIENT WAS CO-OPERATIVE IN THE TESTING SITUATION. THERE WAS NO APPARENT EFFORT TO EITHER EXCESSIVELY MINIMIZE OR EXAGGERATE PERSONAL PROBLEMS.

THIS IS ONE OF THE MOST FREQUENT PROFILE TYPES AMONG PSYCHIATRIC PATIENTS AND IS ONLY VERY RARELY FOUND AMONG NORMALS. THE PSYCHOPATHOLOGY INDICATED BY THE MMPI IS LIKELY TO INVOLVE MULTIPLE NEUROTIC MANISFESTATIONS AND TO BE CHRONIC AND LONG STANDING. THE PREDOMINANT SYMPTOM PICTURE INCLUDES THE DISTRESS SYNDROME (DEPRESSION, ANXIETY, NERVOUSNESS), AND STRONG OBSESSIONAL CHARACTERISTICS. THE DEPRESSION IS MAINLY EXPRESSED BY FEELINGS OF HOPELESSNESS. THE PATIENTS WITH SUCH PROFILE TYPES TEND TO BE SELF-ANALYTICAL AND RUMINATIVELY INTROSPECTIVE. THEY ARE TYPICALLY INTELLECTUALIZERS WHO ARE OVER-IDEATIONAL IN THEIR APPROACH TO SOLVING EMOTIONAL PROBLEMS. THEY COMPLAIN OF CONCENTRATION AND THINKING DIFFICULTIES, AND ARE APT TO SUFFER FROM EXCESSIVE INDECISION, DOUBTS, AND VACILLATION. THEY ARE DESCRIBED AS BEING FEARFUL WORRIERS WHO LACK SELF-ESTEEM AND ARE PRONE TO ENGAGE IN SUICIDAL RUMINATIONS. THEY ALSO FREQUENTLY EXHIBIT THE NEURASTHENIC SYNDROME (WEAKNESS, FATIGUE, LOSS OF INTEREST AND INITIATIVE).

THEIR BASIC PERSONALITY PATTERN IS OFTEN SAID TO BE SCHIZOID, THE PATIENTS TENDING TO WITHDRAW, TO BE SOCIALLY INTROVERSIVE AND DISTANT. DIAGNOSTICALLY THERE IS AN ALMOST EVEN SPLIT BETWEEN VARIOUS TYPES OF SCHIZOPHRENIC REACTIONS, ESPECIALLY PSEUDONEUROTIC SCHIZOPHRENIA, AND SEVERE OBSESSIVE-COMPULSIVE REACTIONS.

THESE PATIENTS MAY RESPOND WELL TO RELATIVELY SHORT, GOAL-DIRECTED, AND RE-EDUCATIVE TYPE OF PSYCHOTHERAPY WHICH DE-EMPHASIZES FURTHER INTROSPECTION, SELF-ANALYSIS, AND GENERAL PREOCCUPATION WITH ONESELF, AND ENCOURAGES THE PATIENT TO MORE EFFECTIVELY SOLVE REAL LIFE PROBLEMS.

IMPRESSION-(1) OBSESSIVE-COMPULSIVE REACTION, SEVERE,

(2) PSEUDONEUROTIC SCHIZOPHRENIA.

Figure 4. Automated standard profile interpretation of MMPI.

based on scale-by-scale analysis is generally more conservative in tone and does not include a diagnostic impression. In comparison with reports produced by the previously cited commercial services, these are briefer, less repetitious, and more focused on basic clinical data. Rather than providing a broad, overall personality description of the subjects, the reports generated here are intended to provide concise data for psychiatric decision making by clinicians. Clinical decision makers at inpatient psychiatric services apparently spend only a few minutes reading clinical reports from outside sources (Miller, 1976). Thus, concise, topical reports seem preferable.

\section{DISCUSSION AND CONCLUSIONS}

Several advantages of the above approach are prominent. By combining several methods of interpretation, a complete report is generated for every patient. The most valid and reliable methods of interpretation are used first. When scale-by-scale analysis is used, statements are organized into a logical report in which contradictions and duplications are eliminated. The entire interpretative system is organized so that statements or rules can be added, deleted, or amended at any time. Thus, the program may be improved using newly published research, evaluative data obtained within the hospital, or additional clinical experience. In a similar way, Brooks and Kleinmuntz (1974) developed an automated computer diagnostic system that improves its accuracy automatically by incorporating feedback on the accuracy of previous decisions into the weighting of items used to make diagnostic decisions.
Information relating to the efficacy of different treat. ments, probable course in the hospital, and recommended outpatient treatment methods for patients with different profile types may be incorporated into this system. As a result, profile interpretation can be made more "interventionally relevant" (Johnson et al., 1976).

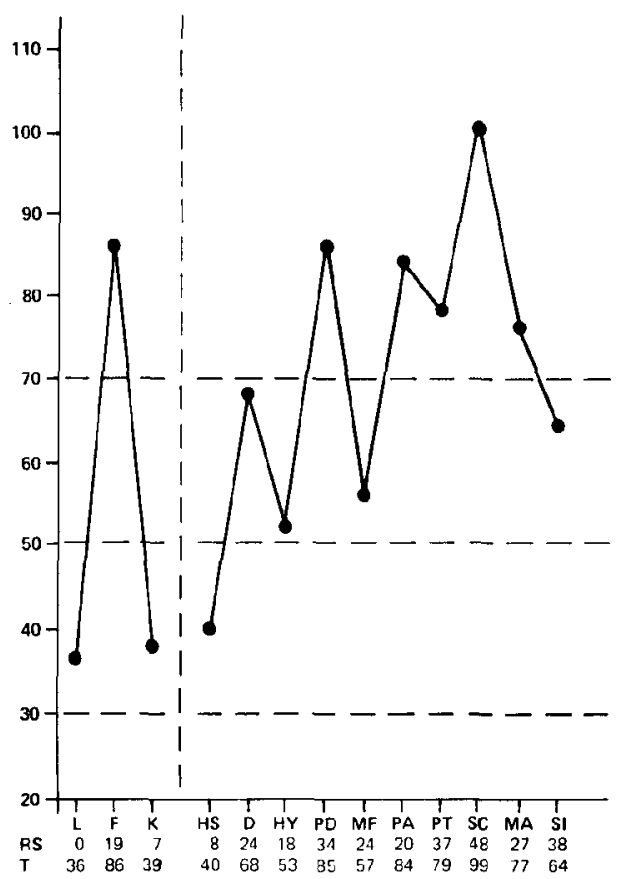

Figure 5. MMPI scores resulting in scale-by-scale interpretation. 
PATIENT NAME

M M P I INTERPRETATION

THE PATIENT WAS CO-OPERATIVE IN THE TESTING SITUATION. THERE WAS NO APPARENT EFFORT TO EITHER EXCESSIVELY MINIMIZE OR EXAGGERATE PERSONAL PROBLEMS.

THIS IS NOT A WELL-KNOWN PROFILE TYPE. THEREFORE, THE FOLLOWING INTERPRETATION SHOULD BE VIEWED WITH CAUTION. THE MMPI SUGGESTS MODERATE CURRENT DISTRESS, CHIEFLY ANXIETY, BUT ALSO NERVOUSNESS, WORRYING, TENSION, DEPRESSION. PERSONS WITH SIMILAR PROFILES ARE LIKELY TO SHOW THE FOLLOWING SYMPTOMS:

FIXED PARANOID BELIEF PATTERNS, THINKING DISTURBANCE,

OBSESSIONAL THINKING.

SUCH PATIENTS ADMIT TO SEVERAL CLASSICAL PSYCHOTIC SYMPTOMS SUCH AS HALLUCINATIONS, DELUSIONS, STRANGE EXPERIENCES, AND FEELINGS OF UNREALITY,

THEY FEEL THAT THEY HAVE HAD AN UNPLEASANT HOME LIFE CHARACTERIZED BY LACK OF LOVE IN THE FAMILY AND PARENTS WHO WERE UNNECESSARILY CRITICAL, NERVOUS, QUARRELSOME, AND QUICKTEMPERED. MINOR OBSTACLES AND FRUSTRATIONS OFTEN ANGER THEM. ENTHUSIASM FOR PROJECTS, PLANS, AND UNDERTAKINGS IS SHORT-LIVED. MOODINESS IS COMMON.

IN ATTITUDES AND CHARACTER, THEY ARE CONSCIENTIOUS, MORALISTIC, UNEMOTIONAL, NONCONFORMING, SELF-CRITICAL, RIGID, SUSPICIOUS. THEY SHOW LITTLE CONCERN ABOUT HEALTH. INCLINATION TOWARD AESTHETIC AND FEMININE INTEREST PATTERNS CAN BE EXPECTED. SCHIZOID MENTATION, CONFUSION, AND STRANGE THOUGHTS AND BELIEFS ARE LIKELY. DAYDREAMING IS FREQUENT. SCATTERED INTERESTS, ENERGIES AND HYPERACTIVE THINKING ARE PROBABLE. PROMINENT DEFENSE MECHANISMS INCLUDE RATIONALIZATION, PROJECTION. THEY TEND TO ESCAPE FROM REALITY PRESSURES AND UNACCEPTABLE IMPULSES TO NEED FULFILLMENT FANTASIES.

IN INTERPERSONAL RELATIONSHIPS, THEY ARE HOSTILE, SUPERFICIAL. POOR FAMILY AND SOCIAL RELATIONSHIPS ARE PROBABLE. THEY ARE EXTREMELY SENSITIVE TO THE REACTIONS OF OTHERS AND FEEL MISUNDERSTOOD BY THEM, WHILE AT THE SAME TIME BEING CONCERNED ABOUT OFFENDING THEM. IN VOCATIONAL WORK, THEY ARE INEFFECTIVE DUE TO SCATTERING OF INTERESTS AND INABILITY TO COMPLETE PROJECTS. MODERATE TO SEVERE LEVELS OF ANXIETY AND TENSION MAKE SIMPLE VOCATIONAL TASKS DIFFICULT. THEY ARE PESSIMISTIC ABOUT THEIR VOCATIONAL FUTURE.

Figure 6. Automated scale-by-scale interpretation of MMPI.

One may also update interpretative rules, based on a regular incoming flow of concurrent and follow-up data concerning patients whose profiles have been interpreted previously.

Further, research may permit equally valid test in. terpretation based on a much smaller set of items. Several researchers have developed decision-tree systems for computerized diagnostic classification or test interpretation (Klein, Honigfeld, \& Feldman, 1973; Kleinmutz \& McLean, 1968). Bürli (1975) concluded that use of branched testing procedures may result in significant reductions in test length with equivalent validity. Successful use of this approach could reduce administrative costs and patient dissatisfaction with lengthy testing procedures.

\section{REFERENCE NOTES}

1. Caldwell, A. B. Recent advances in automated interpretation of the MMPI. Presented at the Fifth Annual Symposium of Recent Development in the Use of the MMPI, Mexico City, February 1970.

2. Lushene, R. E., \& Gilberstadt, H. Validation of VA MMPI computergenerated reports. Paper presented at the Veterans Administration Cooperative Studies Conference, St. Louis, March 1972.

3. Stelmachers, Z. MMPI interpretive paragraphs. Hennepin County Mental Health Center, Minneapolis, Minnesota.

\section{REFERENCES}

BLock, J. The challenge of response sets: Unconfounding meaning, acquiescence, and social desirability in the MMPI. New York: Appleton-Century-Crofts, 1965.

Bringmann, W. G., Balance, W., \& Geisbrecht, C. A. The computer vs. the technologist: Comparison of psychological reports on normal and elevated MMPI profiles. Psychological Reports, 1972, 31, 211-217.

Brooks, R., \& Kleinmuntz, B. Design of an intelligent computer psycho-diagnostician. Behavional Science, 1974, 19, 16-20.

BüRLI, A. [Computer-assisted test administration and branched testing.] Psychologie: Schweizerische Zeitschrift für Psychologie und ihre Anwendungen, 1975, 34, 115-128. (Psychological Abstracts, 1976, 55, No. 1760.)

Carson, R. C. Interpretive manual to the MMPI. In J. N. Butcher (Ed), MMPI: Research developments and clinical applications. New York: McGraw-Hill, 1969.

Daflstrom, W. G., Welsh, G. S., \& Darlstrom, L. E. An MMPI handbook (Vol. 1). Minneapolis: University of Minnesota Press, 1972.

Dunlop, E. Essentials of the automated MMPI. Glendale, Calif: Institute of Clinical Analysis, 1966.

EIchman, W. J. Computerized scoring and interpretive services. In $O$. K. Buros (Ed.), The seventh mental measurements yearbook (Vol. 1). Highland Park, N.J: Gryphon Press, 1972.

Finney, J. C. Programmed interpretation of MMPI and CPI. Archives of General Psychiatry, 1966, 15, 75-81.

FOWLER, R. D. Computer interpretation of personality tests: The automated psychologist. Comprehensive Psychiatry, $1967,8,455-467$ 
Gehring, A., \& Blaser, P. [A computer program for the evaluation and interpretation of the MMPI.] Psychologie, 1972, 31, 292-297. (Psychological Abstracts, 1973, 50, No. 6825.)

Gilberstadr, H. Construction and application of MMPI cade books. In J. N. Butcher (Ed.), MMPI: Research developments and clinical applications. New York: McGraw-Hill, 1969.

Gilberstadt, H. Comprehensive MMPI code book for males. Washington, D.C: U.S. Government Printing Office, 1970.

Gilberstadt, H., \& Duker, J. A handbook for clinical and actuarial MMPI interpretation. Philadelphia: W. B. Saunders, 1965.

Goldberg, L. R. Diagnosticians vs. diagnostic signs: The diagnosis of psychosis vs neurosis from the MMPI. Psychological Monographs, 1965, 79(9, Whole No. 602).

Goldstein, A. M., \& REZniroff, M. MMPI performance in chronic medical illness: The use of computer-derived interpretations. British Journal of Psychiatry, 1972, 120, 157-158.

Gougr, H. G. The $F$ minus $K$ dissimulation index for the MMPI. Journal of Consulting Psychology, 1950, 14, 408-413.

Grayson, H. M., \& BACKER, T. E. Scoring accuracy of four automated MMPI interpretation report agencies. Journal of Clinical Psychology, 1972, 28, 366-370.

Gynther, M. D., Altman, H., \& Sletten, I. W. Replicated correlates of MMPI two-point code types: The Missouri actuarial system. Joumal of Clinical Psychology, 1973, 29, 263-289.

Hedlund, J. L., Morgan, D. W., \& Master, F. D. The Mayo Clinic automated MMPI program: Crossvalidation with psychiatric patients in an army hospital. Journal of Clinical Psychology, 1972, 28, 505-510.

Johnson, J. H., Giannetti, R. A., \& Williams, T. A. Computers in mental health care delivery: A review of the evolution toward interventionally relevant on-line processing. Behavior Research Methods \& Instrumentation, 1976, 8, 83-91.

KLein, D. F., Honigfeld, G., \& Feldoman, S. Prediction of drug effect in personality disorders. Joumal of Nervous and Mental Disease, 1973, 156, 183-198.

KLeINMUNTz, B., \& McLean, R. S. Diagnostic interviewing by digital computer. Behavioral Science, 1968, 13, 75-80.

LACHAR, D. Accuracy and generalizability of an automated
MMPI interpretation system. Journal of Consulting and Clinical Psychology, 1974, 42, 267-273. (a)

LACHAR, D. The MMPI: Clinical assessment and automated interpretation. Los Angeles: Western Psychological Services, 1974. (b)

Lachar, D., Klinge, V., \& Grisell, J. Relative accuracy of automated MMPI narratives generated from adult norm and adolescent norm profiles. Jourmal of Clinical and Consulting Psychology, 1976, 44, 20-24.

Lushene, R. E., O'NeIL, H., JR., \& Dunn, T. Equivalent validity of a completely computerized MMPI. Journal of Personality Assessment, 1974, 38, 353-361.

Marks, P. A., \& SEEMAN, W. Actuarial description of abnormal personality: An atlas for use with the MMPI. Baltimore: Williams \& Wilkins, $1 \% 3$.

MILLER, D. A. The utility of medication-oriented intake information for inpatient psychiatric treatment. Unpublished doctoral dissertation, University of Utah, 1976.

Nichols, D. S. The Goldberg rules in the detection of MMPI code book modal diagnoses. Journal of Clinical Psychology, 1974, 30, 186-191.

Pearson, J. S., \& Swenson, W. M. A user's guide to the Mayo Clinic automated MMPI program. New York: Psychological Corporation, 1967.

Swenson, W. M. Statement library for computer analysis. In P. Marks \& W. Seeman (Eds.), The actuarial description of abnormal personality: $A n$ atlas for use with the MMPI. Baltimore: Williams \& Wilkins, 1963.

WEBB, J. T. Validity and utility of computer-produced MMPI reports with Veterans Administration psychiatric populations. Proceedings of the 78th Annual Convention of the American Psychological Association, 1970, 5, 541-542. (Summary)

WebB, J. T., Miller, M. L., \& Fowler, R. D. Validation of a computerized MMPI interpretation system. Proceedings of the 77 th Annual Convention of the American Psychological Association, 1969, 523-524. (Summary)

Webb, J. T., Miller, M. L., \& Fow Ler, R. D. Extending professional time: A computerized MMPI interpretation service. Journal of Clinical Psychology, 1970, 26, 210-214.

Wiggins, J. S., GoldeERG, L. R., APPElbaUM, M. MMPI content scales: Interpretive norms and correlations with other scales. Journal of Consulting and Clinical Psychology, 1971, 37, 403-410. 